\title{
Comparison of levetiracetam with phenytoin for the prevention of intravenous busulfan-induced seizures in hematopoietic cell transplantation recipients
}

\author{
Kana Akiyama ${ }^{1} \cdot$ Tetsuo Kume $^{1}$ (1) $\cdot$ Masafumi Fukaya ${ }^{2} \cdot$ Ikue Shiki $^{2} \cdot$ Terukazu Enami $^{2} \cdot$ Raine Tatara $^{2}$. \\ Michihiro Shino $^{1} \cdot$ Takashi lkeda $^{2}$
}

Received: 2 May 2018 / Accepted: 1 August 2018 / Published online: 6 August 2018

(c) The Author(s) 2018

\begin{abstract}
Purpose Busulfan is used as a conditioning regimen for hematopoietic stem cell transplantation and is known to cause seizures as a side effect. As various anticonvulsant drugs have been reported, we conducted a retrospective investigation regarding the preventive effects and adverse events associated with different anticonvulsants administered alongside intravenous busulfan (ivBu) in our institution.

Methods We targeted 104 patients who received ivBu at our institution from May 1, 2010 to April 30, 2017. We investigated the seizure prevention rate and adverse events rate under anticonvulsant prophylaxis.

Results There were 70 cases $(67.3 \%)$ of phenytoin administration and 34 cases $(32.7 \%)$ of levetiracetam administration for anticonvulsant therapy. The seizure prevention rate was $98.6 \%$ for phenytoin and $100 \%$ for levetiracetam; seizures occurred in one out of 104 patients. There were no significant differences in the seizure prevention rate depending on the type of anticonvulsant. Further, there were no differences in adverse events.

Conclusions Anticonvulsant prophylaxis is considered necessary for safe conditioning with ivBu. Adverse events associated with the use of levetiracetam are within an acceptable range. Further, levetiracetam is considered useful as a preventive drug against seizures during ivBu administration because it is easy to administer and has ideal pharmacokinetics for supportive care.
\end{abstract}

Keywords Anticonvulsant $\cdot$ Intravenous busulfan $\cdot$ Seizures $\cdot$ Stem cell transplantation

\section{Introduction}

Intravenous busulfan (ivBu) has been used as a conditioning regimen for hematopoietic stem cell transplantation [1-3]. Busulfan is known to cause seizures; at high doses it passes freely through the blood-brain barrier, resulting in high concentrations in the central nervous system, thus increasing the risk of convulsive seizures. Busulfan-induced seizures are generally tonic-clonic in nature. It has been reported

Tetsuo Kume

t.kume@scchr.jp

1 Department of Pharmacy, Shizuoka Cancer Center, 1007, Shimonagakubo, Nagaizumi-cho, Sunto-gun, Shizuoka 411-8777, Japan

2 Division of Hematology and Stem Cell Transplantation, Shizuoka Cancer Center, 1007, Shimonagakubo, Nagaizumi-cho, Sunto-gun, Shizuoka 411-8777, Japan that the incidence of seizures is 10\% (range 1.8-40\%) when high-dose busulfan is used without preventive measures [4]. Drugs used to prevent busulfan-induced seizures must be fast acting, should not increase the toxicity of the conditioning agents, and should not alter the pharmacokinetics of the conditioning regimen $[4,5]$. While the package insert for busulfan recommends anticonvulsant prophylaxis, no information regarding a specific drug or its administration is provided. There are many reports describing the use of antiepileptic drugs, such as phenytoin and valproic acid, as well as benzodiazepines, such as clonazepam or lorazepam, as prophylactic treatments against busulfan-induced seizures $[4,6,7]$. While there are many reported cases of phenytoin use, it reportedly induces drug metabolizing enzymes, thereby interacting with the metabolism of cyclophosphamide, a drug used in the conditioning regimen [8, 9]. More recently, there have been reports of the use of levetiracetam as a prophylaxis against busulfan-induced seizures 
in pediatrics; however, there is little information regarding its use in adults $[5,10,11]$. The pharmacokinetic features of levetiracetam, including approximately $100 \%$ bioavailability and linear pharmacokinetics, enable its usage without therapeutic drug monitoring (TDM) $[12,13]$. Additionally, the drug has no effect on cytochrome P450 metabolic enzymes [14]. In this study, we conducted a retrospective analysis of prophylactic anticonvulsant agents, as well as their adverse effects, when used in cases of ivBu administration at our institution.

\section{Materials and methods}

We included 104 cases of ivBu usage during hematopoietic stem cell transplantation at the Shizuoka Cancer Center from May 1, 2010 to April 30, 2017 in this study. The main study endpoints were seizure and involuntary movement prevention rates during ivBu administration. In addition, the presence of nausea, vomiting, and oral mucositis was assessed from the start of the conditioning regimen to the day of transplantation. Oral mucositis, total bilirubin, and veno-occlusive disease/sinusoidal obstruction syndrome (VOD/SOS) were assessed from the start of the conditioning regimen to 28 days post-transplantation as secondary endpoints to confirm that ivBu-induced adverse events were not enhanced by the use of anticonvulsants. Moreover, neutrophil engraftment was assessed. Neutrophil engraftment was defined as the first day of an absolute neutrophil count $>500$ / $\mu \mathrm{L}$ on three consecutive measurements. The Common Terminology Criteria for Adverse Events (version 4.0) and the Modified Seattle Criteria were used for retrospective assessment of the medical records $[15,16]$.

For this type of study formal consent is not required.

\section{Statistical analysis}

We used Fisher's exact test, and $p$ values $<0.05$ were considered statistically significant. All statistical analyses were performed with EZR version 3.2.2; EZR is a modified version of " $R$ Commander" that includes statistical functions frequently used in biostatistics.

\section{Results}

The patient characteristics are shown in Table 1. A diagnosis of "other" included anaplastic large cell lymphoma, mixed phenotype acute leukemia B/myeloid, Hodgkin's lymphoma/ nodular sclerosis, myelofibrosis, and adult T-cell leukemia/ lymphoma, representative of one individual each. The ivBu $2+\alpha$ conditioning regimen included the use of intravenous busulfan at $6.4 \mathrm{mg} / \mathrm{kg}$ in combination with another
Table 1 Patient characteristics as $N(\%)$ or median (range)

\begin{tabular}{|c|c|c|}
\hline & PHT & LEV \\
\hline$N$ & 70 & 34 \\
\hline Male sex & $46(65.7)$ & $18(52.9)$ \\
\hline Age (years) & $58(17-74)$ & $58(35-69)$ \\
\hline \multicolumn{3}{|l|}{ Diagnosis } \\
\hline AML & $40(57.1)$ & $10(29.4)$ \\
\hline MDS & $24(34.3)$ & $11(32.4)$ \\
\hline CML & $4(5.7)$ & $3(8.8)$ \\
\hline PCNSL & 0 & $5(14.7)$ \\
\hline DLBCL & $2(2.9)$ & 0 \\
\hline Other & 0 & $5(14.7)$ \\
\hline \multicolumn{3}{|l|}{ Donor/stem cell source } \\
\hline Autologous peripheral blood & 0 & $5(14.7)$ \\
\hline Related peripheral blood & $14(20.0)$ & $4(11.8)$ \\
\hline Unrelated peripheral blood & 0 & $5(14.7)$ \\
\hline Unrelated bone marrow & $42(60.0)$ & $10(29.4)$ \\
\hline Unrelated cord blood & $14(20.0)$ & $10(29.4)$ \\
\hline \multicolumn{3}{|l|}{ Conditioning regimen } \\
\hline $\mathrm{ivBu} / \mathrm{CY}$ & $20(28.6)$ & $9(26.5)$ \\
\hline FB4 & $8(11.4)$ & 0 \\
\hline $\mathrm{ATG} / \mathrm{FB} 4 \pm \mathrm{AraC}$ & $37(52.9)$ & $18(52.9)$ \\
\hline $\mathrm{FB} 4 / \mathrm{TBI} \pm \mathrm{AraC}$ & $2(2.9)$ & $4(11.8)$ \\
\hline $\mathrm{ivBu} 2+\alpha$ & $3(4.3)$ & 0 \\
\hline $\mathrm{ivBu} 4+\beta$ & 0 & $3(8.8)$ \\
\hline \multicolumn{3}{|l|}{ Emesis prophylaxis } \\
\hline Granisetron & $70(100)$ & $10(29.4)$ \\
\hline Palonosetron & 0 & $1(2.9)$ \\
\hline Palonosetron + fosaprepitant & 0 & $23(67.6)$ \\
\hline
\end{tabular}

$A M L$ acute myeloid leukemia, $M D S$ myelodysplastic syndrome, $C M L$ chronic myeloid leukemia, $P C N S L$ primary central nervous system lymphoma, $D L B C L$ diffuse large B cell lymphoma, $i v B u / C Y$ intravenous busulfan at $12.8 \mathrm{mg} / \mathrm{kg}+$ cyclophosphamide, $i v B u 2+\alpha$ intravenous busulfan at $6.4 \mathrm{mg} / \mathrm{kg}$ + other drugs, $F B 4$ fludarabine + intravenous busulfan at $12.8 \mathrm{mg} / \mathrm{kg}, A T G$ anti-thymocyte globulin (rabbit), AraC cytarabine, TBI total body irradiation, $i v B u 4+\beta$ intravenous busulfan at $12.8 \mathrm{mg} / \mathrm{kg}$ + other drugs, $P H T$ phenytoin, $L E V$ levetiracetam.

drug. For the ivBu $4+\beta$ conditioning regimen, ivBu was administered at $12.8 \mathrm{mg} / \mathrm{kg}$ in combination with another drug.

Phenytoin and levetiracetam were used as anticonvulsants in $70(67.3 \%)$ and $34(32.7 \%)$ cases, respectively. All cases of prophylaxis using phenytoin were administered intravenously. One case of prophylaxis using phenytoin was started on the initial day of ivBu administration, while all other cases were started the day before ivBu administration. The dose of phenytoin before ivBu administration was $125 \mathrm{mg} /$ day in one case, $150 \mathrm{mg} /$ day in two cases, and $300 \mathrm{mg} /$ day in the remaining cases. After initiation of ivBu administration, the dose of phenytoin was $250 \mathrm{mg} /$ day in two cases and 
$300 \mathrm{mg} /$ day in the remaining cases. All cases of prophylaxis using oral levetiracetam were given $1000 \mathrm{mg} /$ day and began 2 days prior to the start of ivBu administration. Phenytoin or levetiracetam was administered as a prophylactic treatment until the day after the termination of ivBu administration.

Under phenytoin anticonvulsant prophylaxis, the seizure and involuntary movement prevention rates were 98.6 and $87.1 \%$, respectively. Prevention rates associated with levetiracetam were 100 and $97.1 \%$ for seizures and involuntary movements, respectively. There was one confirmed case of a seizure from a patient having received $125 \mathrm{mg} /$ day phenytoin 1 day before ivBu administration; the seizure was identified on the second day of ivBu administration, at which point the conditioning regimen was changed by the attending physician in consideration of the difficulties associated with continuing the existing regimen.

Assessments of the incidence of nausea, vomiting, and oral mucositis are shown in Table 2. Grade one (Gr1) oral mucositis was found in $55.7 \%$ and $\mathrm{Gr} 2$ oral mucositis was found in $2.9 \%$ of patients receiving phenytoin prophylaxis, from the start of the conditioning regimen to transplantation day; in contrast, Gr 1 oral mucositis was found in $38.2 \%$ and $\mathrm{Gr} 2$ oral mucositis was found in $0 \%$ of patients receiving levetiracetam prophylaxis $(p=0.12)$. Gr3 oral mucositis was not observed in either prophylactic treatment group. However, the incidences of oral mucositis in the phenytoin prophylaxis groups were $\mathrm{Gr} 1: 31.4 \%, \mathrm{Gr} 2: 25.7 \%$, and Gr3: $\leq 35.7 \%$ from the start of the conditioning period to

Table 2 Incidence of nausea, vomiting, oral mucositis, and liver toxicity, $N(\%)$

\begin{tabular}{|c|c|c|c|}
\hline & $\operatorname{PHT}(n=70)$ & $\operatorname{LEV}(n=34)$ & $p$ value \\
\hline \multicolumn{4}{|l|}{ Nausea } \\
\hline All grades & $50(71.4)$ & $30(88.2)$ & 0.08 \\
\hline Grade $3 \leq$ & $12(17.1)$ & $1(2.9)$ & 0.06 \\
\hline \multicolumn{4}{|l|}{ Vomiting } \\
\hline All grades & 34 (48.6) & $18(52.9)$ & 0.84 \\
\hline Grade $3 \leq$ & $3(4.3)$ & 0 & 0.55 \\
\hline \multicolumn{4}{|l|}{ Mucositis oral } \\
\hline \multicolumn{4}{|c|}{ Until transplant day } \\
\hline All grades & $41(58.6)$ & $13(38.2)$ & 0.06 \\
\hline Grade $3 \leq$ & 0 & 0 & \\
\hline \multicolumn{4}{|l|}{ Until day 28} \\
\hline All grades & $65(92.9)$ & $32(94.1)$ & 1 \\
\hline Grade $3 \leq$ & $25(35.7)$ & $12(35.3)$ & 1 \\
\hline \multicolumn{4}{|l|}{ T-Bil } \\
\hline All grades & $29(41.4)$ & $10(29.4)$ & 0.28 \\
\hline Grade $3 \leq$ & $2(2.9)$ & 0 & 1 \\
\hline VOD/SOS & $2(2.9)$ & 0 & 1 \\
\hline
\end{tabular}

PHT phenytoin, $L E V$ levetiracetam, $T$-Bil total bilirubin, $V O D / S O S$ veno-occlusive disease/sinusoidal obstruction syndrome
28 days post-transplantation; incidences of oral mucositis were $\mathrm{Gr} 1: 14.7 \%, \mathrm{Gr} 2: 44.1 \%$, and $\mathrm{Gr} 3: \leq 35.3 \%(p=0.18)$ in the levetiracetam prophylaxis group. There were no significant differences in the occurrence of adverse events, including nausea, vomiting, oral mucositis, and liver dysfunction based on differences in anticonvulsant usage.

The median number of days to neutrophil engraftment was 15.5 (range 11-24) days and 15.0 (10-31) days in phenytoin and levetiracetam groups, respectively.

\section{Discussion}

We conducted a retrospective study to assess the types of anticonvulsant drugs and their prophylactic effects when used in cases of ivBu administration. Previous studies have reported that seizures occur at a frequency of $1-40 \%$ in cases of busulfan administration with no prophylactic anticonvulsant use [4, 17]. In our study, seizure prevention rates of 98.6 and $100 \%$ were observed when phenytoin and levetiracetam were used as prophylactic treatments against ivBuinduced seizures, respectively. There were no statistically significant differences between anticonvulsant types. However, a confirmed seizure case was observed with phenytoin prophylaxis, resulting in difficulty with the use of ivBu and a subsequent change in conditioning agent. Previous reports have identified a $1 \%$ frequency in the incidence of seizures even under prophylactic anticonvulsant administration $[18,19]$. ivBu-induced seizures may occur even in the presence of anticonvulsant agents, resulting in a sudden change in the conditioning schedule. Therefore, there is a need for additional prophylactic anticonvulsants to prevent ivBu-induced seizures and avoid sudden changes in the conditioning schedule.

To be used as a prophylactic agent, a drug should not enhance the toxicity associated with the conditioning regimen [4]. No statistically significant differences in nausea and vomiting were observed between the anticonvulsants studied, during the conditioning regimen. The incidence of vomiting in the levetiracetam prophylaxis group was less than that of previous reports $[1,20]$. The combination of palonosetron + fosaprepitant was used for its antiemetic effect in $67.6 \%$ of patients in the levetiracetam prophylaxis group. Palonosetron is a second-generation 5-hydroxytryptamine 3 receptor antagonist that is more effective in the suppression of delayed nausea and vomiting than the first-generation 5-hydroxytryptamine 3 receptor antagonist, granisetron [21]. In addition, nausea and vomiting are alleviated by a combination of 5-hydroxytryptamine 3 receptor antagonists and the neurokinin-1 receptor antagonist, fosaprepitant; fosaprepitant is the pro-drug of aprepitant [22, 23]. The ability to use both substances in recent years has resulted in improvements in the control of vomiting over that observed in past 
reports. This is in contrast to oral mucositis, with no noted differences in its high incidence rate. Moreover, the presentation of VOD/SOS did not differ significantly from previous reports $[6,10,20,24]$. Furthermore, the median number of days to neutrophil engraftment did not differ significantly in a previous systematic review [25], and it may be assumed that anticonvulsant administration had no significant effects on adverse events associated with ivBu administration.

This study assessed the use of phenytoin or levetiracetam as anticonvulsant agents. TDM is sometimes required with phenytoin, as it displays non-linear pharmacokinetics. In contrast, levetiracetam is approximately $100 \%$ bioavailable, with no effects on cytochrome P450 metabolic enzymes. Consequently, levetiracetam can be used orally or intravenously without consideration of the cytochrome P450 enzyme system or TDM [12-14]. While slight involuntary movements were observed, there was an absence of seizures in the levetiracetam prophylaxis group. An oral mucositis score of Gr2 or less was observed from the start of conditioning to transplantation, enabling drugs to be administered orally throughout the ivBu administration period. Oral levetiracetam can be administered continually as a prophylactic agent against ivBu-induced seizures; therefore, medical personnel may consider oral levetiracetam administration to be a more convenient method than that required for phenytoin.

Limitations exist in the current study. First, this was a retrospective study carried out in a single institution with a limit to the drugs that could be used as anticonvulsants. The second was the inability to conduct pharmacokinetic monitoring of ivBu. As such, we were unable to evaluate the effects of phenytoin and levetiracetam on ivBu pharmacodynamics. The third limitation concerns difficulties in adjusting the dose of phenytoin, attributable to the short administration period, with a consequent inability to conduct TDM for phenytoin. Therefore, it is unclear whether optimal blood concentrations of phenytoin were maintained during ivBu administration. Fourth, direct hematological toxicity induced by levetiracetam could not be evaluated owing to strong myelosuppression of myeloablative conditioning [26, 27].

In conclusion, prophylactic anticonvulsant administration is necessary to facilitate transplantations without sudden changes in conditioning schedules. Further, our results show that levetiracetam can be used to effectively prevent busulfan-induced seizures in adults. Moreover, the use of levetiracetam is convenient for medical staff, as it can be administered orally and TDM is not required. Importantly, the absence of adverse events induced with oral administration of levetiracetam during ivBu administration is indicative of its application for continued administration and its convenience of use by medical staff. These results support clinical decision making by providing evidence for the use of levetiracetam during ivBu conditioning. In the future, it is necessary to consider prospective studies to validate supportive care for better busulfan-induced seizure prevention.

\section{Compliance with ethical standards}

Conflict of interest The authors declare that they have no conflict of interest.

Ethical standards The Shizuoka Cancer Center institutional review board approved our study design and publication of the results. The Shizuoka Cancer Center ethics committee waived the requirement for informed consent because of the retrospective nature of the study. This article does not contain any studies with animals performed by any of the authors.

Open Access This article is distributed under the terms of the Creative Commons Attribution 4.0 International License (http://creativeco mmons.org/licenses/by/4.0/), which permits unrestricted use, distribution, and reproduction in any medium, provided you give appropriate credit to the original author(s) and the source, provide a link to the Creative Commons license, and indicate if changes were made.

\section{References}

1. Kim SW, Mori SI, Tanosaki R, Fukuda T, Kami M, Sakamaki H, Yamashita T, Kodera Y, Terakura S, Taniguchi S, Miyakoshi S, Usui N, Yano S, Kawano Y, Nagatoshi Y, Harada M, Morishima Y, Okamoto S, Saito AM, Ohashi Y, Ueda R, Takaue Y (2009) Busulfex (i.v. BU) and CY regimen before SCT: Japanese-targeted phase II pharmacokinetics combined study. Bone Marrow Transplant 43:611-617

2. Bredeson C, LeRademacher J, Kato K, Dipersio JF, Agura E, Devine SM, Appelbaum FR, Tomblyn MR, Laport GG, Zhu X, McCarthy PL, Ho VT, Cooke KR, Armstrong E, Smith A, Rizzo JD, Burkart JM, Pasquini MC (2013) Prospective cohort study comparing intravenous busulfan to total body irradiation in hematopoietic cell transplantation. Blood 122:3871-3878

3. Lee JH, Joo YD, Kim H, Ryoo HM, Kim MK, Lee GW, Lee JH, Lee WS, Park JH, Bae SH, Hyun MS, Kim DY, Kim SD, Min YJ, Lee KH (2013) Randomized trial of myeloablative conditioning regimens: busulfan plus cyclophosphamide versus busulfan plus fludarabine. J Clin Oncol 31:701-709

4. Eberly AL, Anderson GD, Bubalo JS, McCune JS (2008) Optimal prevention of seizures induced by high-dose busulfan. Pharmacotherapy 28:1502-1510

5. Floeter AE, McCune JS (2017) Levetiracetam for the prevention of busulfan-induced seizures in pediatric hematopoietic cell transplantation recipients. J Oncol Pharm Pract 23:344-349

6. Sato M, Kako S, Matsumoto K, Oshima K, Akahoshi Y, Nakano H, Ugai T, Yamasaki R, Wada H, Ishihara Y, Sakamoto K, Kawamura K, Ashizawa M, Terasako-Saito K, Kimura S, Nakasone H, Kikuchi M, Tanihara A, Yamazaki R, Tanaka Y, Kanda J, Nishida J, Morita K, Kanda Y (2015) Pharmacokinetics study of oncedaily intravenous busulfan in conditioning regimens for hematopoietic stem cell transplantation. Int J Hematol 101:497-504

7. Diaz-Carrasco MS, Olmos R, Blanquer M, Velasco J, SánchezSalinas A, Moraleda JM (2013) Clonazepam for seizure prophylaxis in adult patients treated with high dose busulfan. Int J Clin Pharm 35:339-343

8. Slattery JT, Kalhorn TF, McDonald GB, Lambert K, Buckner CD, Bensinger WI, Anasetti C, Appelbaum FR (1996) Conditioning 
regimen-dependent disposition of cyclophosphamide and hydroxycyclophosphamide in human marrow transplantation patients. J Clin Oncol 14:1484-1494

9. de Jonge ME, Huitema AD, van Dam SM, Beijnen JH, Rodenhuis S (2005) Significant induction of cyclophosphamide and thiotepa metabolism by phenytoin. Cancer Chemother Pharmacol 55:507-510

10. Soni S, Skeens M, Termuhlen AM, Bajwa RP, Gross TG, Pai V (2012) Levetiracetam for busulfan-induced seizure prophylaxis in children undergoing hematopoietic stem cell transplantation. Pediatr Blood Cancer 59:762-764

11. Yazal Erdem A, Azık F, Tavil B, Teber S, Tunç B, Uçkan D (2014) Busulfan triggers epileptic seizures under levetiracetam and valproic acid therapy. Pediatr Transplant 18:412-413

12. Ramael S, De Smedt F, Toublanc N, Otoul C, Boulanger P, Riethuisen JM, Stockis A (2006) Single-dose bioavailability of levetiracetam intravenous infusion relative to oral tablets and multiple-dose pharmacokinetics and tolerability of levetiracetam intravenous infusion compared with placebo in healthy subjects. Clin Ther 28:734-744

13. Tan J, Paquette V, Levine M, Ensom MHH (2017) Levetiracetam clinical pharmacokinetic monitoring in pediatric patients with epilepsy. Clin Pharmacokinet 56:1267-1285

14. Perucca E, Gidal BE, Baltès E (2003) Effects of antiepileptic comedication on levetiracetam pharmacokinetics: a pooled analysis of data from randomized adjunctive therapy trials. Epilepsy Res 53:47-56

15. Common Terminology Criteria for Adverse Events, version 4.0. NCI, NIH, DHHS. https://evs.nci.nih.gov/ftp1/CTCAE/CTCAE _4.03/CTCAE_4.03_2010-06-14_QuickReference_5x7.pdf. Accessed 8 May 2017

16. McDonald GB, Hinds MS, Fisher LD, Schoch HG, Wolford JL, Banaji M, Hardin BJ, Shulman HM, Clift RA (1993) Veno-occlusive disease of the liver and multiorgan failure after bone marrow transplantation: a cohort study of 355 patients. Ann Intern Med 118:255-267

17. Leon-Rodriguez E, Rivera-Franco MM (2016) Minimal incidence of neurotoxicity without prophylaxis during busulfan-based conditioning regimen in patients undergoing stem cell transplantation. Int J Hematol 104:644-646

18. De La Camara R, Tomas JF, Figuera A, Berberana M, FernandezRañada JM (1991) High dose busulfan and seizures. Bone Marrow Transplant 7:363-364

19. Caselli D, Rosati A, Faraci M, Podda M, Ripaldi M, Longoni D, Cesaro S, Lo Nigro L, Paolicchi O, Maximova N, Menconi MC, Ziino O, Cicalese MP, Santarone S, Nesi F, Aricò M, Locatelli F,
Prete A (2014) Risk of seizures in children receiving busulphancontaining regimens for stem cell transplantation. Biol Blood Marrow Transplant 20:282-285

20. Andersson BS, Kashyap A, Gian V, Wingard JR, Fernandez H, Cagnoni PJ, Jones RB, Tarantolo S, Hu WW, Blume KG, Forman SJ, Champlin RE (2002) Conditioning therapy with intravenous busulfan and cyclophosphamide (IV BuCy2) for hematologic malignancies prior to allogeneic stem cell transplantation: a phase II study. Biol Blood Marrow Transplant 8:145-154

21. Saito M, Aogi K, Sekine I, Yoshizawa H, Yanagita Y, Sakai H, Inoue K, Kitagawa C, Ogura T, Mitsuhashi S (2009) Palonosetron plus dexamethasone versus granisetron plus dexamethasone for prevention of nausea and vomiting during chemotherapy: a double-blind, double-dummy, randomised, comparative phase III trial. Lancet oncol 10:115-124

22. Uchida M, Kato K, Ikesue H, Ichinose K, Hiraiwa H, Sakurai A, Muta T, Takenaka K, Iwasaki H, Miyamoto T, Teshima T, Shiratsuchi M, Suetsugu K, Nagata K, Egashira N, Akashi K, Oishi R (2013) Efficacy and safety of aprepitant in allogeneic hematopoietic stem cell transplantation. Pharmacotherapy 33:893-901

23. Uchida M, Ikesue H, Miyamoto T, Kato K, Suetsugu K, Ichinose K, Hiraiwa H, Sakurai A, Takenaka K, Muta T, Iwasaki H, Teshima T, Shiratsuchi M, Egashira N, Akashi K, Oishi R (2013) Effectiveness and safety of antiemetic aprepitant in Japanese patients receiving high-dose chemotherapy prior to autologous hematopoietic stem cell transplantation. Biol Pharm Bull 36:819-824

24. Chaudhry H, Bruce AJ, Wolf RC, Litzow MR, Hogan WJ, Patnaik MS, Kremers WK, Phillips GL, Hashmi SK (2016) The incidence and severity of oral mucositis among allogeneic hematopoietic stem cell transplantation patients: a systematic review. Biol Blood Marrow Transplant 22:605-616

25. Ben Barouch S, Cohen O, Vidal L, Avivi I, Ram R (2016) Busulfan fludarabine vs busulfan cyclophosphamide as a preparative regimen before allogeneic hematopoietic cell transplantation: systematic review and meta-analysis. Bone Marrow Transplant 51:232-240

26. Bacigalupo A, Ballen K, Rizzo D, Giralt S, Lazarus H, Ho V, Apperley J, Slavin S, Pasquini M, Sandmaier BM, Barrett J, Blaise D, Lowski R, Horowitz M (2009) Defining the intensity of conditioning regimens: working definitions. Biol Blood Marrow Transplant 15:1628-1633

27. Léger F, Nguyen L, Puozzo C (2009) Exposure equivalence between IV $(0.8 \mathrm{mg} / \mathrm{kg})$ and oral $(1 \mathrm{mg} / \mathrm{kg})$ busulfan in adult patients. Eur J Clin Pharmacol 65:903-911 